Article

\title{
Monfortinho Thermal Water-Based Creams: Effects on Skin Hydration, Psoriasis, and Eczema in Adults
}

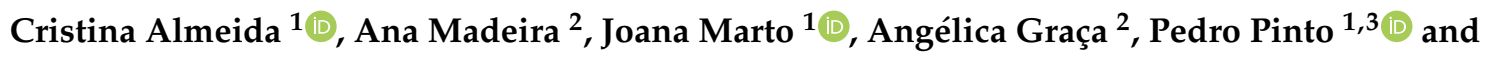 \\ Helena Ribeiro ${ }^{1, * \text { [D }}$ \\ 1 Research Institute for Medicines (iMed.ULisboa), Faculty of Pharmacy, Universidade de Lisboa, \\ Lisboa 1649003, Portugal; calmeida@ff.ulisboa.pt (C.A.); jmmarto@ff.ulisboa.pt (J.M.); \\ geral@phdtrials.com (P.P.) \\ 2 Faculty of Pharmacy, Universidade de Lisboa, Lisboa 1649003, Portugal; anar.madeira@gmail.com (A.M.); \\ angelica_graca@hotmail.com (A.G.) \\ 3 PhD Trials, Rua das Murtas, Lisboa 1700309, Portugal \\ * Correspondence: hribeiro@campus.ul.pt; Tel.: +351-2179-46400
}

Received: 19 August 2019; Accepted: 13 September 2019; Published: 15 September 2019

check for updates

\begin{abstract}
The use of mineral water for therapeutic purposes has varied from century to century and from country to country. Its effectiveness depends on the individual experiences of the population and their cultural traditions. Usually, the waters recommended for dermatological treatment are hot springs that contain sulfur or more recently, silicon. The mechanisms by which mineral waters actuate in dermatological disorders are still not clear but it is believed that they involve thermal, mechanical, chemical, immunologic, and anti-oxidant reactions and enzymatic activity. The aim of this study is to characterize the thermal waters of Monfortinho, one of the oldest Portuguese spas, their potential use for the preparation of dermatological formulations (creams), and their effectiveness on the treatment of skin disorders (psoriasis and eczema). To accomplish this, cream formulations with different contents of thermal water were developed. The formulations were characterized in terms of thermal water analysis and physicochemical properties and their effects were studied by skin biometrics in adults (mean age of 54.3 years old) through skin hydration evaluation and evaluated in clinical studies on 22 patients with psoriasis and eczema. The results showed that all the formulations improved the skin hydration and have beneficial effects in relieving the symptoms of psoriasis and other disorders, but no significant differences were observed when thermal water was used (compared to laboratory ultra-pure water).
\end{abstract}

Keywords: thermal water; creams; psoriasis; eczema; skin biometrics; clinical studies

\section{Introduction}

Portugal is very rich in mineral waters and spas [1], "with 35 spas currently operating in this country". Of these, 15 are recommended for the treatment of skin disorders and Monfortinho spa belongs to this group. The water of Monfortinho emerges at a maximum temperature of $28.2^{\circ} \mathrm{C}$ in Fonte Santa spring, it is hyposaline, bicarbonated, with sodium, calcium, and magnesium, and it has one of the highest silica contents among Portuguese spa waters, which allows rapid regeneration of skin conditions and mucous from the digestive and respiratory systems [2].

There are various dermatological disorders for which treatment with thermal waters are recommended, such as skin diseases and skin reactions (rashes, hives, psoriasis, lichen, acne and rosacea) $[3,4]$. The mechanisms by which natural mineral waters act in the treatment of dermatologic disorders are still poorly understood, but studies have shown that these waters may trigger thermal, mechanical, chemical, and immunomodulatory processes; they have antioxidant properties and may 
also act on enzymatic activities [5-7]. Nevertheless, thermal waters are known to provide comfort and cosmetics containing them are often used to enhance the appearance of the skin [8].

The biological effects of mineral water are related to its chemical composition and to some physical properties, especially the concentration of the predominant compounds (mainly inorganic) as well as with the presence of some trace elements.

Research on the use of thermal water in skin diseases aims to assess the effects of thermal therapy through clinical trials, identify the specific properties of each natural mineral water and its effects in vivo and in vitro, to validate the potential therapeutic interest of the incorporation of the natural mineral water in topical creams [4,5].

Natural mineral water is present in various cosmetic products that are currently marketed by various international brands [4], such as Avène, La Roche Posay, and Uriage [9,10]. In Portugal, there has also been an increased interest from spas to start the development of skin cosmetics that incorporate thermal waters in their composition [5].

In this study we evaluated the thermal water, from the Monfortinho spa, suitable for the treatment of dermatologic diseases at three levels: (i) physical and chemical characterization (total mineralization, electrical conductivity, major anions and cations, presence of trace elements, $\mathrm{pH}$, acidity and redox potential); (ii) influence of the percentage of thermal water in topical creams on the hydration capacity (epidermal capacitance) and transepidermal water loss (TEWL); and iii) health benefits of the creams formulated with thermal water at two concentrations on human volunteers with skin problems, mainly psoriasis (clinical study).

\section{Materials and Methods}

\subsection{Physicochemical Analysis of Thermal Water}

Ultra-pure water was produced on a Milli Q Gradient A10 system, from Millipore (Molsheim, France).

The conductivity was determined with a CyberScan CON 200, supplied by Eutech Instruments (Thermo Fisher Scientific Inc., Waltham, MA, USA), and the calibration and control of the equipment was made with several conductivity standards $\left(84,147,1413\right.$, and $\left.12880 \mu \mathrm{S} / \mathrm{cm}, 25^{\circ} \mathrm{C}\right)$ supplied by Reagecon (Shannon, Co. Clare, Ireland).

The $\mathrm{pH}$ was measured using a $\mathrm{pH}$ meter, Crison model micropH 2002 (Barcelona, Spain) with a glass electrode (Crison, Barcelona, Spain), calibrated using the $\mathrm{pH}$ standards (pH 4, $\mathrm{pH} 7, \mathrm{pH} 6$ and pH 9) supplied by the same company.

The turbidity was determined with a EUTECH TN-100/T-100, supplied by Eutech Instruments (Thermo Fisher Scientific Inc.), and the calibration and control of the equipment was made with several conductivity standards $(0.02,20,100$ and 800 UNT) supplied by Eutech Instruments (Thermo Fisher Scientific Inc, Waltham, MA, USA).

The dissolved oxygen was determined with an inoLab ${ }^{\circledR}$ Laboratory Oxygen Meter, Models Oxi 740, WTW (VWR, Portugal).

The total dissolved solids were determined by gravimetric method at $180^{\circ} \mathrm{C}$ using a Memmert oven, model ULM-700 (Memmert, Germany).

Absorption spectrophotometry was used to determine the color and the concentrations of nitrate, nitrite, ammonia, sulphate, phosphate, sulfide, zinc, iron, and silicon, using a double beam UV/Visible spectrophotometer HITACHI U-2000 (Tokyo, Japan).

Fluoride was analyzed by a potentiometric method with a fluoride combination ion selective electrode from Thermo Scientific, model 9609BNWP (Thermo Fisher Scientific Inc, Waltham, MA, USA) and a Crison potentiometer, $\mathrm{pH}$ meter model GLP22 (Crison, Barcelona, Spain).

Trace elements (aluminum, antimony, arsenic, barium, beryllium, cadmium, lead, cobalt, copper, chromium, manganese, mercury, nickel, selenium, and vanadium) were determined by electrothermal atomic absorption spectrometry (EAAS) with a Perkin Elmer Zeeman Atomic Spectrometer 4110ZL and Autosampler AS-72 from Perkin Elmer (Norwalk, CT, USA). 
Sodium and potassium were analyzed by flame photometry using a 400 Flame Photometer Corning 450 (Corning Limited, Essex, UK).

Hardness, alkalinity, dissolved carbon dioxide, permanganate index, and calcium were analyzed by titrimetric methods.

All analytical methods for water analysis were standard procedures described in the Standard Methods for Examination of Water and Wastewater Analysis (SMEWWA) and in official procedures [11,12].

\subsection{Processing and Physicochemical Characterization of the Creams}

To prepare the creams the oily and aqueous phases were heated separately to $75{ }^{\circ} \mathrm{C}$, then the oily phase was added to the water phase and the system was mixed with constant agitation (Helipath 130 r.p.m.) until the temperature dropped to $30^{\circ} \mathrm{C}$.

Three creams (O/W emulsions) were formulated and prepared with thermal water at two concentrations and with ultra-pure laboratory water. The oily phase was composed of a surfactant (Ceteareth-12 and ceteareth-20) 3\%, a thickening agent (cetyl alcohol) 5\%, and an emollient (decyl oleate) $4.5 \%$, while the water phase contained a humectant (glycerin) $5 \%$, preservative (phenoxyethanol) $0.2 \%$, and water up to $100 \%$. A control containing ultra-pure water (MilliQ) and two thermal creams containing thermal water and concentrated thermal water (2:1) were named C-B1, C-1, and C-2, respectively (Table 1). Concentrated thermal water (C-2) was prepared by evaporation of water to $50 \%$ of its initial volume, using a rotary evaporator (Heidolph, Laborota 4001 , Germany) at $90^{\circ} \mathrm{C}$.

Table 1. Composition of the three creams tested.

\begin{tabular}{cccc}
\hline \multirow{2}{*}{ Ingredients (Chemical Name) } & \multicolumn{3}{c}{ Qualitative and Quantitative Composition $\%(w / w)$} \\
\cline { 2 - 4 } & C-B1 & C-1 & C-2 \\
\hline Ceteareth-12 (and) Ceteareth-20 & 3.0 & 3.0 & 3.0 \\
Cetyl alcohol & 5.0 & 5.0 & 5.0 \\
Decyl oleate & 4.5 & 4.5 & 4.5 \\
Glycerin & 5.0 & 5.0 & 5.0 \\
Phenoxyethanol & 0.2 & 0.2 & 0.2 \\
Ultra-pure laboratory water & q.s. $100 \%$ & - & - \\
Thermal water & - & q.s. $100 \%$ & q.s. $100 \%$ \\
Concentrated thermal water (2:1) & - & - &
\end{tabular}

The apparent viscosity and rheological profile were evaluated at room temperature, using a Brookfield Rotation Viscosimeter ${ }^{\circledR}$, RV DV-II, Small sample amount (approximately $25 \mathrm{~mL}$ ) with a spindle 27 (Brookfield Engineering Laboratories, USA). The shear rate [1/s] versus shear stress [Pa] plots were obtained by submitting the samples to a shear rate sweep from 0.6 to $60 / \mathrm{s}$ and up and down for $7.5 \mathrm{~min}$. $\mathrm{pH}$ values were determined using a pH-meter S20 Seven easy $\mathrm{pH}$, Mettler Toledo (Merck, Darmstadt, Germany), as described elsewhere [13].

\subsection{Skin Biometrics Evaluation}

The moisture content in the stratum corneum is important for cosmetic applications. The skin hydration was evaluated by epidermal capacitance and transepidermal water loss (TEWL) using a Corneometer CM 825 (Courage + Khazaka Electronic GmbH) and a Tewameter TM 210 (Courage + Khazaka Electronic GmbH, Germany). These are indispensable parameters for the evaluation of the water barrier function of the skin and are basic measurements in all kinds of applications.

In this study, the three cream formulations (not diluted) were tested in forearms of healthy volunteers randomly selected in an experimental protocol. A control area in the arm where no cream was applied was chosen as the control. Before use, all formulations under study were transferred to 
opaque white tubes with a corresponding identification code. Thus, neither the volunteers nor the responsible investigator had any knowledge of which cream was being tested.

The distribution of the cream on the forearms was defined according to a simple procedure of alternating between the right and left arm. The creams were applied to the corresponding forearm twice a day for 28 consecutive days. In the days of skin biometrics evaluation, the cream was applied after the measurement. Volunteers evenly applied about $5 \mathrm{mg} / \mathrm{cm}^{2}$ of cream in an area of $10 \times 5 \mathrm{~cm}$, simulating a normal use of the product massaging in 3 circular movements. During the study, the volunteers also kept all their hygiene habits, avoiding any changes in the type of cleaning products used.

A minimized and double-blind study was performed. This protocol was approved by the local Ethical Committee and respected the Helsinki Declaration and Good Clinical Practice studies on cosmetic products. The study was conducted under the supervision of a dermatologist who participated in the evaluation of irritation/allergic reactions to the tested formulations. All participants gave their informed consent. A minimum of 12 volunteers were defined as acceptable for this study. The inclusion criteria in this study were: age range of 18-65 years, feminine gender, skin phototype between I-IV, no skin diseases in the arms and forearms, no marks (tattoos, scars) in the arms and forearms, and arms and forearms with little hair. This study also had exclusion criteria, such as volunteers with systemic disease, pregnancy, autoimmune pathology, serious pathology in the 6 months prior to the beginning of the study (including cancer, myocardial infarction, diabetes), use of any topical medication at the site of assessment, use of any anti-inflammatory systemic medication in the period up to 1 month prior to study initiation or 2 weeks in case of antibiotics, fever for more than $24 \mathrm{~h}$ on the 8 days before the beginning of the study, use of drugs or alcohol, beach sunbathing during the course of the study, and participation in other cosmetic or clinical studies in the previous two weeks. On the day of the skin biometrics evaluation, the volunteers had an acclimatization period of 20-30 $\mathrm{min}$ in the laboratory $\left(21^{\circ} \mathrm{C}, 50 \%\right.$ relative humidity), so that the skin parameters were measured under the same conditions throughout the study.

\subsection{Clinical Study}

The creams were prescribed for 30 patients with psoriasis, atopic dermatitis, and eczema with different stages of the disease, as standard clinical practice. The prescription of the creams was "apply twice a day as a thin layer with massage". The observational study was authorized by the hospital's ethic committee and was conducted in 22 patients after receiving their written informed consent. Patients with advanced diseases were excluded. Patients with psoriasis and eczema were evaluated by the physician and skin response was registered. Erythema, pruritus, and flaking were evaluated by the physician. The moisture content (epidermal capacitance) of the skin was also measured.

\subsection{Statistical Analysis}

Differences in the intergroup over time were calculated by 1-way ANOVA using Excel software from Microsoft. A $P$-value of less than 0.05 was considered statistically significant.

\section{Results and Discussion}

\subsection{Physicochemical Analysis of Thermal Water}

Monfortinho mineral water (thermal water) has a low mineral content and an acidic $\mathrm{pH}$ (Tables 2 and 3). The most significant elements in its composition are: bicarbonate/alkalinity $\left(\mathrm{HCO}^{3-}\right)$, calcium $\left(\mathrm{Ca}^{2+}\right)$, magnesium $\left(\mathrm{Mg}^{2+}\right)$, sodium $\left(\mathrm{Na}^{+}\right)$, silicon $\left(\mathrm{SiO}_{2}\right)$, and chloride $\left(\mathrm{Cl}^{-}\right)$. The water is characterized by its content in silicon, which seems to be the trace element of main interest. 
Table 2. Physicochemical analysis of Monfortinho thermal water: inorganic and physical parameters $(\mathrm{n}=3)$.

\begin{tabular}{|c|c|c|}
\hline Parameter & Units & Results \\
\hline \multicolumn{3}{|c|}{ Inorganic and Physical Factors } \\
\hline Alkalinity & $\mathrm{mg} / \mathrm{L} \mathrm{CaCO}_{3}$ & 2.5 \\
\hline Ammonia & $\mathrm{mg} / \mathrm{L} \mathrm{NH}$ & $<0.05 *$ \\
\hline Boron & $\mathrm{mg} / \mathrm{L} \mathrm{B}$ & $<0.17$ * \\
\hline Chloride & $\mathrm{mg} / \mathrm{L} \mathrm{Cl}$ & 3.7 \\
\hline Conductivity $\left(20^{\circ} \mathrm{C}\right)$ & $\mu \mathrm{S} / \mathrm{cm}$ & 38 \\
\hline Dissolved carbon dioxide & $\mathrm{mg} / \mathrm{L} \mathrm{CO} 2$ & 27 \\
\hline \multirow{2}{*}{ Dissolved oxygen } & $\mathrm{mg} / \mathrm{L} \mathrm{O}_{2}$ & 7.5 \\
\hline & $\%$ Saturation & 87 \\
\hline Fluoride & $\mathrm{mg} / \mathrm{L} \mathrm{F}$ & 0.05 \\
\hline Hardness & $\mathrm{mg} / \mathrm{L} \mathrm{CaCO}_{3}$ & 17 \\
\hline Nitrate & $\mathrm{mg} / \mathrm{L} \mathrm{NO}_{3}$ & $<5.0 *$ \\
\hline Nitrite & $\mathrm{mg} / \mathrm{L} \mathrm{NO}_{2}$ & $<0.01$ * \\
\hline Ortho-phosphate & $\mathrm{mg} / \mathrm{L} \mathrm{PO}_{4}$ & $<0.05 *$ \\
\hline Permanganate index & $\mathrm{mg} / \mathrm{L} \mathrm{O}_{2}$ & 0.67 \\
\hline $\mathrm{pH}\left(25^{\circ} \mathrm{C}\right)$ & $\mathrm{pH}$ scale & 5.7 \\
\hline Silicon & $\mathrm{mg} / \mathrm{L} \mathrm{SiO}_{2}$ & 16 \\
\hline Sulfide & $\mathrm{mg} / \mathrm{L} \mathrm{S}$ & $<0.17^{*}$ \\
\hline Sulphate & $\mathrm{mg} / \mathrm{L} \mathrm{SO}_{4}$ & $<5.0 *$ \\
\hline Total dissolved solids (TDS) & $\mathrm{mg} / \mathrm{L}$ & 53 \\
\hline True color & $\mathrm{mg} / \mathrm{L} \mathrm{Pt} / \mathrm{Co}$ & $<0.50$ * \\
\hline Turbidity & UNT & 0.17 \\
\hline
\end{tabular}

$*<\mathrm{LOQ}$, limit of quantification.

Table 3. Metal analysis of Monfortinho thermal water $(n=3)$.

\begin{tabular}{ccc}
\hline Parameter & Units & Results \\
\hline & Metals \\
\hline Aluminum & $\mu \mathrm{g} / \mathrm{L} \mathrm{Al}$ & $<30^{*}$ \\
Antimony & $\mu \mathrm{g} / \mathrm{L} \mathrm{Sb}$ & $<2.0^{*}$ \\
Arsenic & $\mu \mathrm{g} / \mathrm{L} \mathrm{As}$ & $<1.0^{*}$ \\
Barium & $\mu \mathrm{g} / \mathrm{L} \mathrm{Ba}$ & $<60^{*}$ \\
Beryllium & $\mu \mathrm{g} / \mathrm{L} \mathrm{Be}$ & $<2.0^{*}$ \\
Cadmium & $\mu \mathrm{g} / \mathrm{L} \mathrm{Cd}$ & $<1.0^{*}$ \\
Calcium & $\mathrm{mg} / \mathrm{L} \mathrm{Ca}$ & 1.6 \\
Chromium & $\mu \mathrm{g} / \mathrm{L} \mathrm{Cr}$ & $<10^{*}$ \\
Cobalt & $\mu \mathrm{g} / \mathrm{L} \mathrm{Co}$ & $<4.0^{*}$ \\
Copper & $\mu \mathrm{g} / \mathrm{L} \mathrm{Cu}$ & $<10^{*}$ \\
Iron & $\mu \mathrm{g} / \mathrm{L} \mathrm{Fe}$ & $<20^{*}$ \\
Lead & $\mu \mathrm{g} / \mathrm{L} \mathrm{Pb}$ & $<6.0^{*}$ \\
Magnesium & $\mathrm{mg} / \mathrm{L} \mathrm{Mg}$ & 2.7 \\
Manganese & $\mu \mathrm{g} / \mathrm{L} \mathrm{Mn}$ & $<15^{*}$ \\
Mercury & $\mu \mathrm{g} / \mathrm{L} \mathrm{Hg}$ & $<0.30^{*}$ \\
Nickel & $\mu \mathrm{g} / \mathrm{L} \mathrm{Ni}$ & $<6.0^{*}$ \\
Potassium & $\mathrm{mg} / \mathrm{L} \mathrm{K}$ & 0.90 \\
Selenium & $\mu \mathrm{g} / \mathrm{L} \mathrm{Se}$ & $<1.0^{*}$ \\
Sodium & $\mathrm{mg} / \mathrm{L} \mathrm{Na}$ & 3.3 \\
Vanadium & $\mu \mathrm{g} / \mathrm{L} \mathrm{V}$ & $<5.0^{*}$ \\
Zinc & $\mathrm{mg} / \mathrm{L} \mathrm{Zn}$ & $<0.20^{*}$ \\
\hline
\end{tabular}

$*<\mathrm{LOQ}$, limit of quantification.

When compared to other spring waters, such as Avène, La Roche Posay, Vichy, and Uriage, the Monfortinho water presents low contents of sodium, potassium, calcium, magnesium, chlorides, sulfates, and nitrates. These already commercialized waters have diverse mineral concentrations and 
they have been used in dermatology to treat certain skin conditions, such as atopic dermatitis and skin dryness. Softness, suppleness, and skin comfort were the prominent features induced by the waters, as described by the Bacle study [8].

Because of the low mineral content of Monfortinho thermal water, even after its concentration, it is expected that the cream will be smoother and better scattered on the skin, promoting a greater hydration compared to other SPA waters, namely Avène, La Roche Posay, Vichy, and Uriage. Because exposure to hard water is thought to be a risk factor for eczema [14], it is expected that this hyposaline thermal water may contribute to a greater receptivity of the skin to the cream prepared with it.

\subsection{Physicochemical Characterization of the Creams}

The prepared creams presented white color with an odorless and homogeneous texture. The $\mathrm{pH}$ values of the formulations ranged between 5.4 and 6.4, all pH-compatible with the skin. The values of apparent viscosity obtained varied from 100 to 120 Pa.s. All the creams had a shear thinning rheological behavior with no thixotropy (Figure 1). In summary, the results show that the formulations prepared are compatible with the skin.

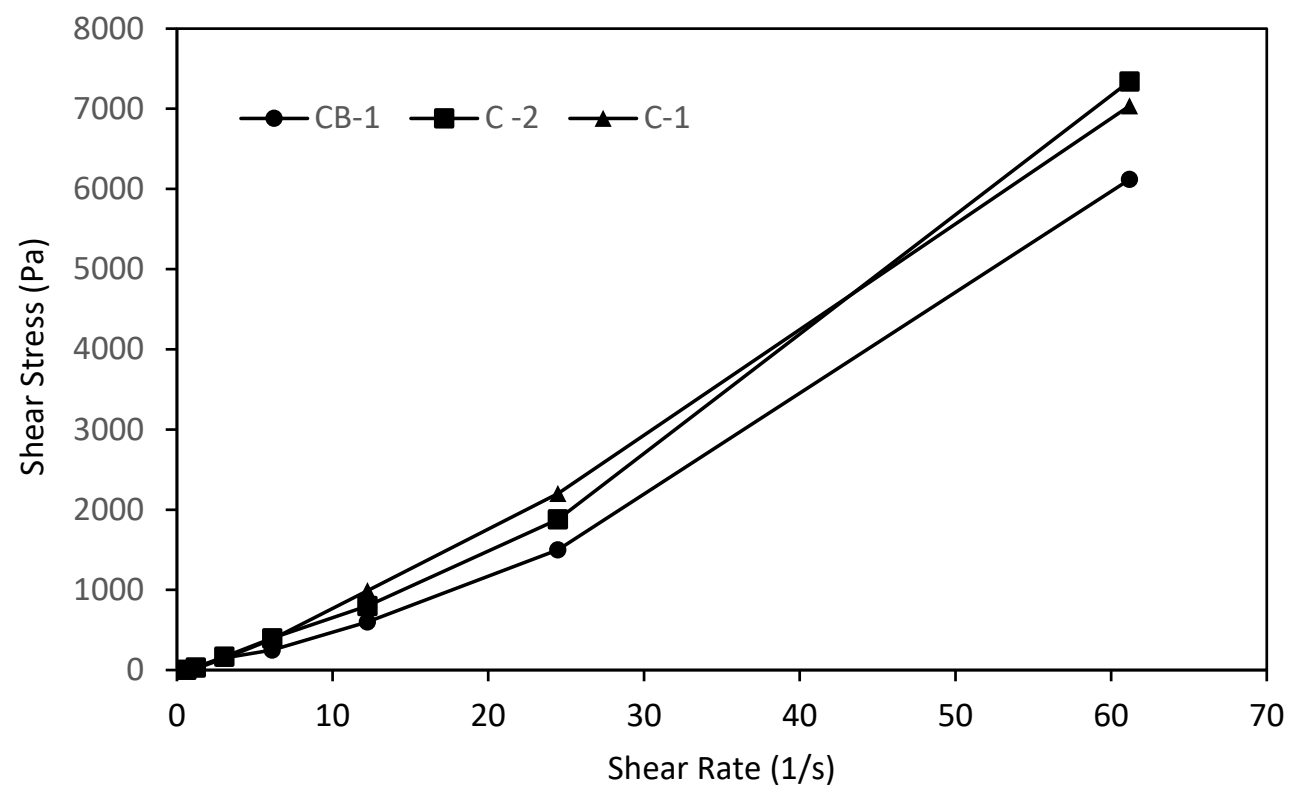

Figure 1. Different creams flow curves: cream with concentrated thermal water 2:1 (C-2), cream with thermal water (C-1), and cream with laboratory water (CB-1).

\subsection{Skin Biometrics Evaluation}

The measuring principle of epidermal capacitance is based on the extreme difference between the water dielectric constant and substances that have lower values. The changes in capacitance contents vary with the water content of the skin. All creams present the same excipients with humectant properties. Glycerin is reported to increase water binding in the Stratum corneum (SC). It has also been reported that the excellent skin moisturization effect of glycerin is due to high accumulation of glycerin in the SC. Glycerin forms a persisting deposit/reservoir in the depth of the SC within the lipids, without disruption of the liquid crystallinity and lamellar structure [15-18].

The data obtained did not reveal any significant differences between the three creams tested throughout the entire study, but showed higher values of epidermal capacitance after 14 days of treatment when compared to the control area (Figure 2). The fact that the control area presents lower hydration values than the anatomic area where the creams were applied may be due to the absence of the humectant agent. The results suggest that the water used in this study have no impact on epidermal capacitance. 


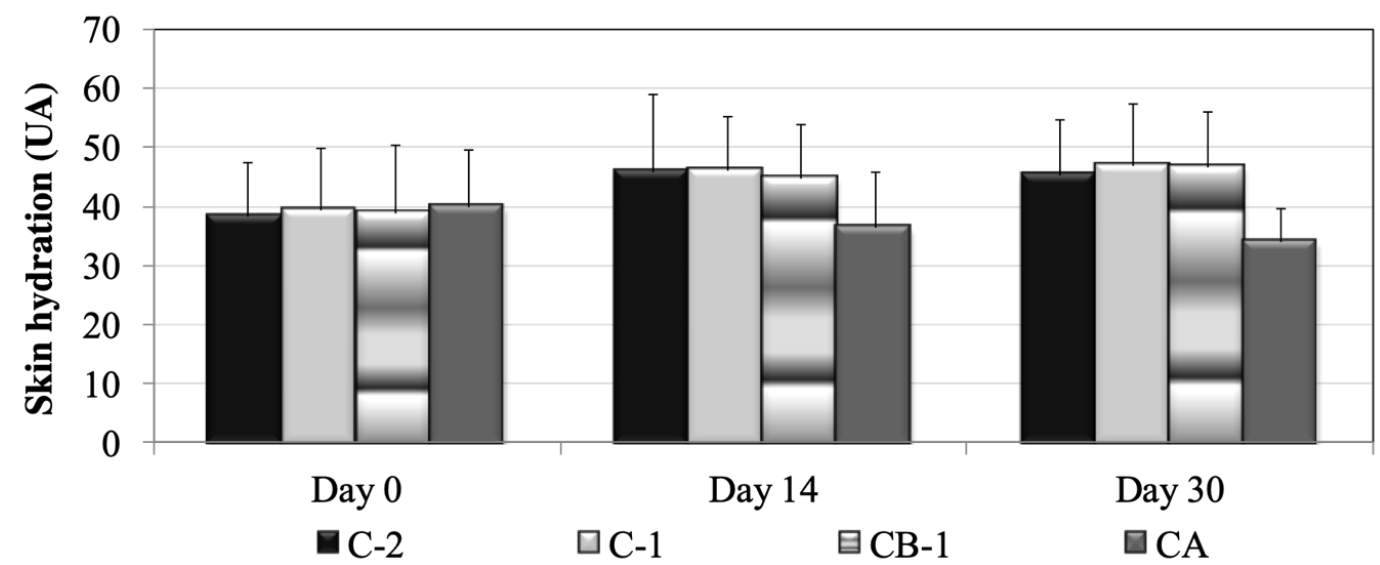

Figure 2. Skin surface hydration over 30 days of treatment with different cream formulations: cream with concentrated thermal water 2:1 (C-2), cream with thermal water (C-1), cream with laboratory water (CB-1), and evaluation of skin without cream (control area or CA). (mean $\pm S D, n=12$ ).

Concerning TEWL, no significant differences were found among the creams and between these and the control (Figure 3). These results are unexpected, given that the creams have a small amount of a non-occlusive emollient (4.5\% of decyl oleate) and the water is its largest constituent. Water is abundant in moisturizers, but it evaporates following application, leaving a lipid residue [19]. In this study, creams were prepared with minimum amounts of excipients that could influence the water activity on skin. Comparing the skin biometrics results, between the creams and the control area, no significant differences in the parameter analysis were observed. These results could also be due to the fact, that lipids are the main ingredients that improve the skin barrier recovery.

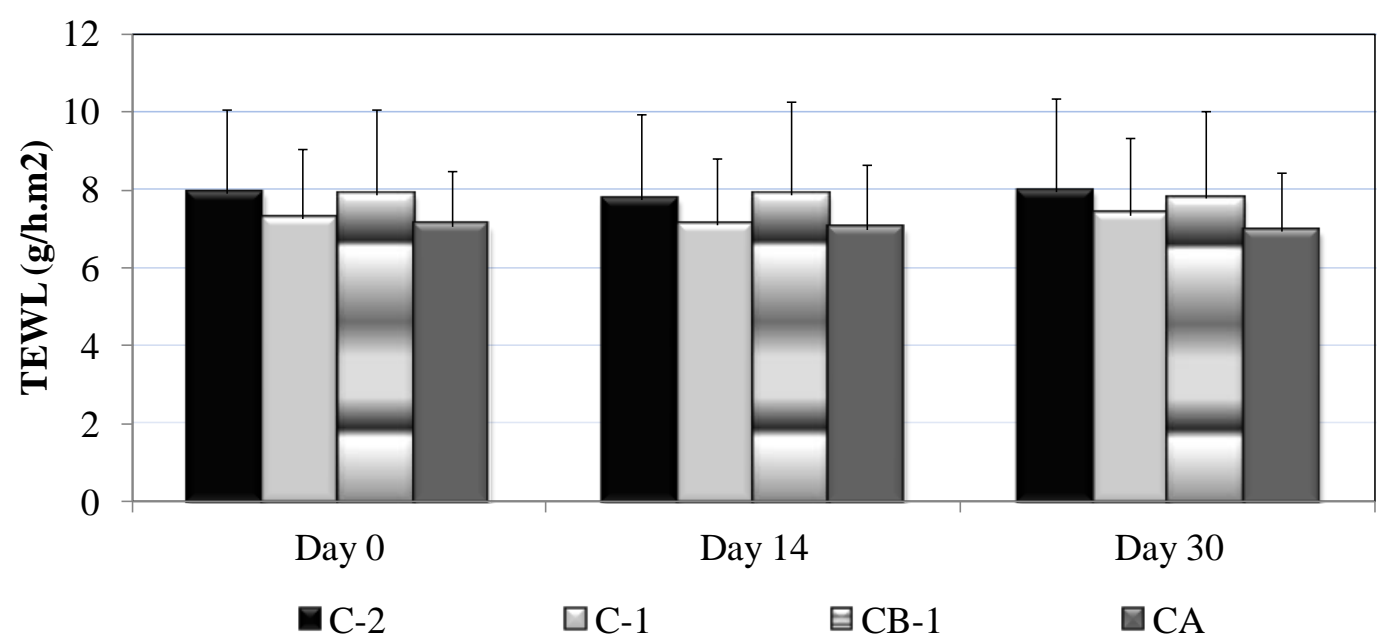

Figure 3. Transepidermal water loss (TEWL) over 30 days of treatment with different cream formulations: cream with concentrated thermal water 2:1 (C-2), cream with thermal water (C-1), cream with laboratory water (CB-1), and evaluation of skin without cream (Control area). (mean $\pm S D, n=12$ ).

\subsection{Clinical Study}

The clinical evaluation of the formulations with thermal water (normal or double concentrated 2:1) against the formulation with laboratory water was carried out in 30 patients of the Monfortinho spa with skin disorders. A total of 22 patients completed the treatment (73\%) during their control in the medical clinic of Monfortinho spa (15-day treatment). Patients had a mean age of 54.3 years, with a minimum age of 18 and a maximum age of 83 years, respectively.

The beneficial effects on skin hydration (epidermal capacitance) of the creams prepared with three types of water (CB-1, C-1, and C-2) were evaluated in volunteers with skin disorders (mainly psoriasis 
and eczema). The skin hydration of each patient with cream application and without cream application was also evaluated by the ratio between both values of skin hydration (Figure 4). In particular it is not possible to evaluate TEWL on the clinical study, by the physician, since this procedure is very sensitive and the conditions did not allow this assessment. As known, the TEWL using open chamber instruments is restricted to horizontal skin surfaces because of the interference from natural air convection [20].

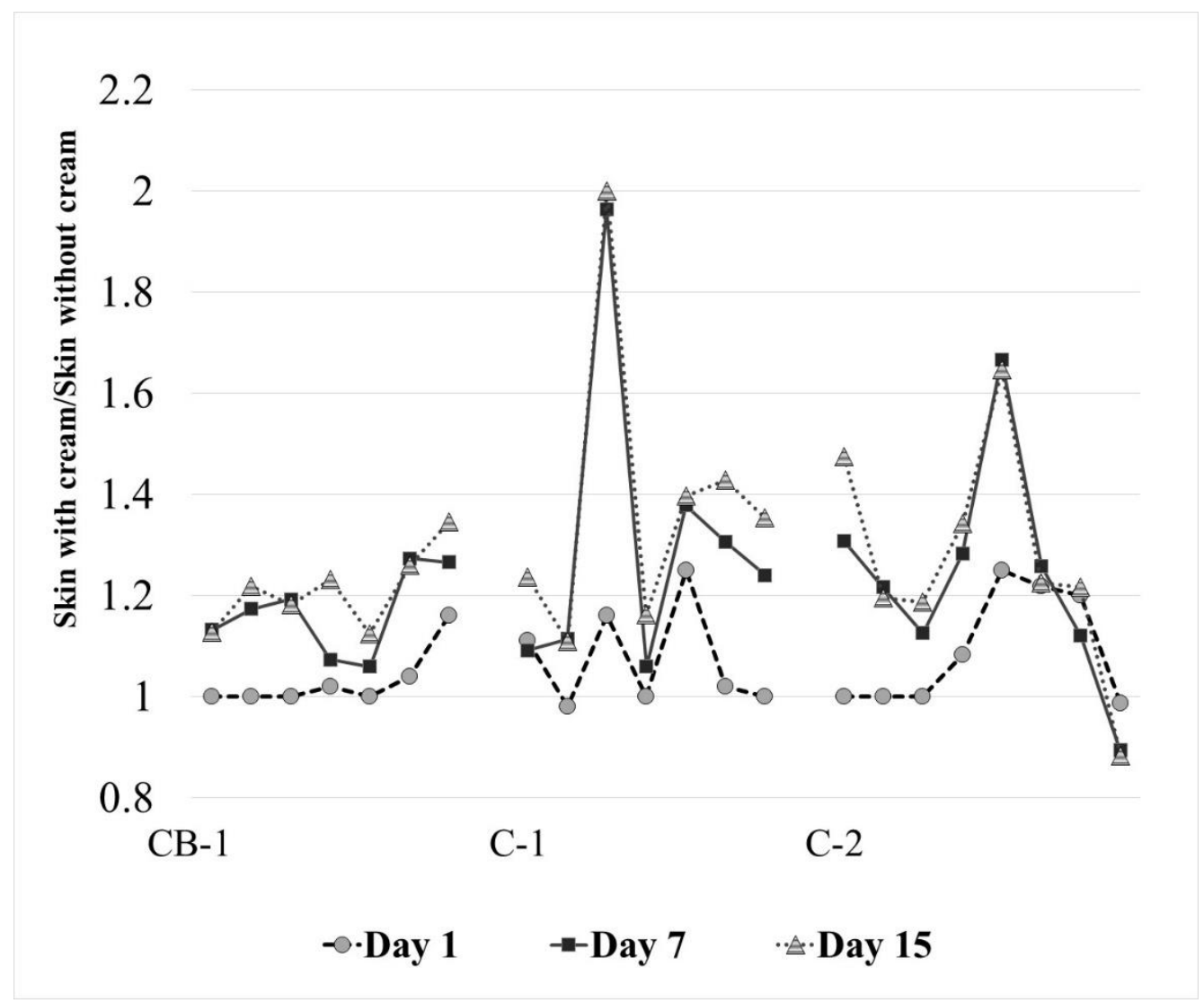

Figure 4. Effects of the creams in skin hydration (UA) of patients with psoriasis: ratio between values obtained with creams prepared with three types of water (cream with laboratory water (CB-1), cream with thermal water (C-1), cream with concentrated thermal water 2:1 and (C-2)) and with no cream application.

Although the results showed no statistically significant differences ( $p$-value $>0.05$ ), the quotient of the degree of skin hydration without and after application of the cream over time (days 1-15) were different because the hydration of their skin improved noticeably. This improvement was higher in patients who applied the cream prepared with thermal water.

Figure 4 shows the obtained results. The data for both creams formulated with thermal water (normal and concentrated) were quite similar.

These results can be due to the low values of calcium and magnesium (low hardness) in both waters (natural and concentrated) used in the creams formulation. The potential undesirable effects of hardness [14] were not observed, even in concentrated thermal water, possibly because they were overcome by the presence of other elements, such as silicium and sulphates. Therefore, the potential beneficial effect associated with the increase of trace elements' concentration in the cream prepared with concentrated thermal water was also overcome by the undesirable effect associated with the increase of water hardness. These results were also observed by other authors. Hyposaline water rich in sulphate, such as Leopoldine spa water, showed potential anti-inflammatory effects on human skin affected by psoriasis [21]. Goldman et al. [22] performed a clinical trial on the effects of low mineral and 
high mineral-content spring water in post-procedure cutaneous inflammation and patient discomfort. The results showed that the effects of the low mineral-content spring water were better when compared to the high mineral content spring water. Our results also confirm the results previously obtained in other trials $[14,20,22]$ that hyposaline waters are better at treating psoriasis.

The clinical part of this study also focused on the qualitative assessment of symptoms, namely the improvement of erythema, itching, and flaking in patients with psoriasis, eczema, or dermatitis. The results are shown in Table 4, where zero (0) means "no improvement" and one (1) represents "improvement." Again, there were no statistically significant differences $(P$-value $>0.05)$ between the results obtained with the three formulations. The data revealed an incidence of positive results or qualitative improvement of erythema by $86 \%, 71 \%$, and $50 \%$ for treatments with laboratory ultra-pure water (CB-1), Monfortinho thermal water (C-1), and concentrated thermal water (C-2), respectively.

Table 4. Effects of each cream formulation (CB-1, C-1, C-2) in the symptoms of different skin disorders in 22 patients from Monfortinho spa.

\begin{tabular}{|c|c|c|c|c|c|c|c|}
\hline & Case Code & Age & Skin Disorder & Location & Erythema & Itching & Flaking \\
\hline \multirow{7}{*}{ CB-1, $n=7$} & 29 & 60 & Psoriasis & Elbow & 0 & 0 & 0 \\
\hline & 26 & 77 & Psoriasis & Left arm & 1 & 1 & 1 \\
\hline & 19 & 73 & Psoriasis & Forearm & 1 & 0 & 1 \\
\hline & 17 & 46 & Psoriasis & Left elbow & 1 & 1 & 1 \\
\hline & 9 & 73 & Psoriasis & Leg & 1 & 1 & 0 \\
\hline & 24 & 65 & Psoriasis & Elbow & 1 & 1 & 0 \\
\hline & 4 & 38 & Psoriasis & Left shoulder & 1 & 1 & 1 \\
\hline \multirow{7}{*}{$C-1, n=7$} & 23 & 82 & Dermatitis & Leg & 0 & 0 & 0 \\
\hline & 20 & 27 & Psoriasis & Arm & 0 & 1 & 1 \\
\hline & 11 & 12 & Psoriasis & Chest & 1 & 1 & 1 \\
\hline & 3 & 53 & Psoriasis & Forearm & 1 & 1 & 1 \\
\hline & 27 & 35 & Psoriasis & Left foot & 1 & 1 & 1 \\
\hline & 28 & 83 & Psoriasis & Knee & 1 & 1 & 1 \\
\hline & 26 & 61 & Psoriasis & Elbow & 1 & 1 & 1 \\
\hline \multirow{8}{*}{$C-2, n=8$} & 7 & 55 & Psoriasis & Arms & 1 & 1 & 1 \\
\hline & 30 & 63 & Psoriasis & Elbows & 0 & 0 & 1 \\
\hline & 21 & 66 & Psoriasis & Right hand & 0 & 0 & 0 \\
\hline & 25 & 52 & Psoriasis & Left arm & 1 & 0 & 0 \\
\hline & 22 & 35 & Psoriasis & Forearm & 0 & 1 & 1 \\
\hline & 15 & 18 & Atopic eczema & Arm & 1 & 1 & 1 \\
\hline & 1 & 55 & Atopic eczema & Right elbow & 0 & 1 & 1 \\
\hline & 2 & 66 & Psoriasis & Right elbow & 1 & 1 & 1 \\
\hline
\end{tabular}

The positive results of itching symptoms were $71 \%, 86 \%$, and $63 \%$ for treatments with laboratory water (CB-1), Monfortinho thermal water (C-1), and concentrated thermal water (C-2), respectively. The positive results of flaking symptoms were $57 \%, 86 \%$, and $75 \%$ for treatments with laboratory water (CB-1), Monfortinho thermal water (C-1), and concentrated thermal water (C-2), respectively.

Dryness is frequently linked to an impaired barrier function observed, for example, in atopic skin, psoriasis, ichthyosis, and contact dermatitis [23]. All creams helped on the prevention of chafing and dryness of most sensible skins affected by any of these skin disorders, including the one formulated with laboratory water (CB-1). This positive effect was higher, but not statistically significant, for itching and flaking skin disorders when the treatment was done with the cream formulated with thermal water (C-1). Additional studies with a larger population may clarify these putative differences.

\section{Conclusions}

Cosmetics, unlike drugs, are not used to diagnose or treat a disease, but to improve appearance and satisfy consumers. The skin feel of personal care products has been shown to improve consumer experiences, with both physical and psychological effects. Indeed, the psychological part also plays a role on the effect of these products. 
Research should continue to be a differentiating factor of the spa treatment, to give it a scientific validation. To achieve this goal, it is fundamental to stimulate the involvement of universities and research institutes, medical spas, hospitals, and motivate a transdisciplinary approach involving researchers from different areas. This obviously demands an adequate funding support from the state.

This study showed that all the creams tested had a positive effect on the skin because of the increase in skin hydration, when compared with the area that received no treatment. The clinical studies showed an increased relief of symptoms associated with psoriasis, eczema, or dermatitis. However, no statistically significant differences were observed when comparing the tested formulations, including the one prepared with laboratory ultra-pure water. An advantage is that the formulations are easy to prepare and economically viable, and showed beneficial effects in decreasing the dryness of the skin in the studied diseases.

However, further studies are necessary to unravel the possible therapeutic effects of the Monfortinho thermal waters.

Author Contributions: A.M. prepared the formulations. J.M. and A.G. performed the in vitro characterization studies. P.P. designed and supervised the in vivo studies. H.R. and C.A. designed and supervised the experiments. All authors contributed to the manuscript preparation.

Funding: This work was funded by FCT-Fundação para a Ciência e a Tecnologia (UID/DTP/04138/2013) and PhD Trials.

Acknowledgments: The authors would like to acknowledge Ana Martins for the manuscript revision.

Conflicts of Interest: The authors state no conflict of interest and have received no payment in preparation of this manuscript.

\section{References}

1. Picoto, A. Mineral water and spas in Portugal. Clin. Dermatol. 1996, 14, 637-639. [CrossRef]

2. Association TdP. Termas de Monfortinho. Available online: http://www.termasdeportugal.pt/estanciastermais/ Termas-de-Monfortinho (accessed on 27 April 2016).

3. Ghersetich, I.; Freedman, D.; Lotti, T. Balneology today. J. Eur. Acad. Dermatol. 2000, 14, 346-348. [CrossRef]

4. Seite, S. Thermal waters as cosmeceuticals: La Roche-Posay thermal spring water example. Clin. Cosmet. Investig. Dermatol. 2013, 6, 23-28. [CrossRef] [PubMed]

5. Ferreira, M.O.; Costa, P.C.; Bahia, M.F. Effect of São Pedro do Sul thermal water on skin irritation. Int. J. Cosmet. Sci. 2010, 32, 205-210. [CrossRef] [PubMed]

6. Gattu, S.; Maibach, H. Enhanced Absorption through Damaged Skin: An Overview of the in vitro Human Model. Ski. Pharmacol. Physiol. 2010, 23, 171-176. [CrossRef] [PubMed]

7. Gattu, S.; Maibach, H. Modest but Increased Penetration through Damaged Skin: An Overview of the in vivo Human Model. Skin Pharmacol. Phys. 2011, 24, 2-9. [CrossRef] [PubMed]

8. Meges, S.; Lauze, C.; Dupuy, P.; Bacle, I.; MacLeod, P. Sensory analysis of four medical spa spring waters containing various mineral concentrations. Int. J. Dermatol. 1999, 38, 784-786.

9. Fabre, P. Avène 2016. Available online: http://www.eau-thermale-avene.fr/eau-thermale/apaisement-antiirritation/eau-thermale-avene (accessed on 10 April 2018).

10. Uriage. Thermal Center: l'eau de la Peau 2016. Available online: http://www.uriage.com/AA/en/the-thermalcenter (accessed on 10 April 2018).

11. Clesceri, L.; Greenberg, A.; Eaton, A. Standard Methods for the Examination of Water and Wastewater, 21th ed.; American Public Association: Washington, DC, USA, 2005.

12. International Organization for Standardization I. Water Quality-Determination of Permanganate Index; ISO 8467:1993; Internation Organization for Standardization: Geneve, Switzerland, 1993.

13. Neves, A.; Marto, J.; Duarte, A.; Gonçalves, L.M.; Pinto, P.; Figueiredo, A.C.; Ribeiro, H.M. Characterization of Portuguese Thymbra capitata, Thymus caespititius and Myrtus communis essential oils in topical formulations. Flavour Fragr. J. 2017, 32, 392-402. [CrossRef]

14. Sengupta, P. Potential Health Impacts of Hard Water. Int. J. Prev. Med. 2013, 4, 866-875. [PubMed] 
15. Ertel, K.; Warner, R.; Boissy, W. Effect of moisturizers on the structure of lipids in the outer stratum corneum of humans. In Dry Skin and Moisturizers, Chemistry and Function, 2nd ed.; Lodén, M., Maibach, H., Eds.; CRC Press: Boca Raton, FL, USA, 2006.

16. Fluhr, J.B.; Berardesca, A.; Glycerol, E. Just a moisturizer? biological and biophysical effects. In Dry Skin and Moisturizers, Chemistry and Function, 2nd ed.; Lodén, M., Maibach, H., Eds.; CRC Press: Boca Raton, FL, USA, 2006.

17. Lodén, M. Treatments Improving Skin Barrier Function. Curr. Probl. Dermatol. 2016, 49, 112-122. [PubMed]

18. Lodén, M. Effect of moisturizers on epidermal barrier function. Clin. Dermatol. 2012, 30, 286-296. [CrossRef] [PubMed]

19. Ribeiro, H.; Marto, J.; Raposo, S.; Agapito, M.; Isaac, V.; Chiari, B.G.; Lisboa, P.F.; Paiva, A.; Barreiros, S.; Simões, P. From coffee industry waste materials to skin-friendly products with improved skin fat levels. Eur. J. Lipid Sci. Technol. 2013, 115, 330-336. [CrossRef]

20. Barkat, A.K.; Naveed, A.; Abder, M.; Farid, M. A Novel Cassia fistula (L.)-Based Emulsion Elicits Skin Anti-Aging Benefits in Humans. Cosmetics 2015, 2, 368-383.

21. Tsoureli-Nikita, E.; Menchini, G.; Ghersetich, I.; Hercogova, J.; Tsoureli-Nikita, E. Alternative treatment of psoriasis with balneotherapy using Leopoldine spa water. J. Eur. Acad. Dermatol. Venereol. 2002, 16, 260-262. [CrossRef] [PubMed]

22. Goldman, M.P.; Merial-Kieny, C.; Nocera, T.; Méry, S. Comparative benefit of two thermal spring waters after photodynamic therapy procedure. J. Cosmet. Dermatol. 2007, 6, 31-35. [CrossRef] [PubMed]

23. Lodén, M. Role of topical emollients and moisturizers in the treatment of dry skin barrier disorders. Am.J. Clin. Dermatol. 2003, 4, 771-788. [CrossRef] [PubMed]

(C) 2019 by the authors. Licensee MDPI, Basel, Switzerland. This article is an open access article distributed under the terms and conditions of the Creative Commons Attribution (CC BY) license (http://creativecommons.org/licenses/by/4.0/). 